\title{
A dimensão ética da sistematização do exercício profissional
}

\author{
The ethical dimension of the systematization of professional exercise
}

Isabela Sarmet de Azevedo*

\begin{abstract}
Resumo:
Este artigo tem como foco a sistematização do exercício profissional do assistente social. Os objetivos do estudo foram analisar a unidade entre teoria e prática e a dimensão ética do exercício profissional; discutir a importância da sistematização do exercício profissional para todos os campos de atuação profissional; e articular a sistematização do exercício profissional, com as condições de trabalho e as demandas de usuários das políticas sociais. O estudo compreende uma revisão de literatura sobre o tema da sistematização no Serviço Social, em que se identificou que o conjunto de conhecimentos específicos que circundam "fazer profissional" e que poderiam qualificar as ações dos assistentes sociais não tem sido abordado com profundidade. A proposta de análise é criar procedimentos de sistematização que permitam realizá-la em consonância com o Código de Ética Profissional e Lei de Regulamentação da Profissão (Lei no 8.662/93). Quanto às dificuldades apontadas pelos autores para a prática da sistematização destacam-se o fator tempo, as condições de trabalho desfavoráveis e as limitações postas pela própria formação profissional. Mesmo considerando todos os avanços, a sistematização do exercício profissional no Serviço Social ainda é escassa, desarticulada e pouco expressiva.
\end{abstract}

Palavras-chave: Sistematização. Ética. Exercício profissional.

\begin{abstract}
:
This article focuses on the systematization of the professional social worker. The objectives of the study were to analyze the unity between theory and practice and the ethical dimensions of professional practice; discuss the importance of the systematization of the professional practice for all fields of professional activity; and articulate systematization of professional exercise, with the working conditions and the demands of users of social policies. Comprised a review of the literature on the topic of systematization in Social Service, where it was identified that the set of specific knowledge that surround "professional" and that could qualify the actions of social workers has not been addressed in dept. The proposed analysis is to establish procedures for systematization to accomplish it in line with the Code of Professional ethics and Law to regulate the profession (Law no 8.662/93). As regards the difficulties pointed out by the authors for the practice of systematic stand out the time factor, the poor working conditions and the limitations posed by their vocational training. Even considering all the advances, the systematization of professional practice in Social Service is still scarce, disjointed and less expressive.
\end{abstract}

\footnotetext{
- Doutora pela Pontifícia Universidade Católica de São paulo. Professora Adjunta do Departamento de Serviço da Universidade Federal Fluminense, Campos dos Goytacazes, RJ. E-mail: isabela sarmet@uol.com.br
} 
Keywords: systematization; ethics; professional exercise

\section{Introdução}

O presente artigo é resultado de um convite feito pelo CRESS/7ạ Região para ministrar um minicurso sobre o tema Sistematização do Exercício Profissional, com a seguinte ementa: a unidade entre teoria e prática e a dimensão ética do exercício profissional; a importância da sistematização do exercício profissional para todos os campos de atuação profissional; e articulação da sistematização do exercício profissional, com as condições de trabalho e as demandas de usuários das políticas sociais.

O interesse pela temática decorre da prática docente, nas disciplinas de Ética Profissional, Estágio Supervisionado em Serviço Social e Monografia na Graduação em Serviço Social, na Universidade Federal Fluminense, onde são acompanhados discentes nas diferentes instituições, em processos de sistematização do exercício profissional. Essa aproximação tem conduzido a profícuas reflexões sobre a dimensão ética do exercício profissional. Também o projeto de pesquisa desenvolvido academicamente - Legislação Social, políticas públicas e exercício profissional - aponta para a necessidade do profissional de Serviço Social sistematizar suas práticas, de acordo com as demandas identificadas, com o objetivo de se fortalecerem para o enfrentamento da questão social.

Esperamos, com o presente estudo, fomentar processos de sistematização não só no âmbito acadêmico, mas nos espaços sócio-ocupacionais dos assistentes sociais, de modo que a dimensão ética do exercício profissional possa não só ser compreendida na sua importância, mas vivenciada pela categoria profissional no dia a dia do trabalho, conforme previsto no Código de Ética Profissional. Afinal, é a sistematização do exercício profissional que permite ao assistente social se apropriar de sua própria experiência pela construção do sentido de sua vivência no campo das políticas sociais. A construção de sentido implica selecionar e organizar informações, estabelecer relações, construir sínteses, para interpretar experiências e vivências.

\section{A unidade entre teoria e prática e a dimensão ética do exercício profissional}


O Serviço Social é uma profissão atravessada por relações de poder, com clara dimensão política. Do mesmo modo, o Código de Ética Profissional (CEP) do Assistente Social deve ser compreendido como um instrumento educativo e orientador do trabalho do profissional. "Assim, é mais do que um conjunto de normas, deveres e proibições; é parte da ética profissional: ação prática mediada por valores que visam interferir na realidade, na direção da sua realização objetiva, produzindo um resultado concreto". (BARROCO; TERRA, 2012, p. 35). Não estamos falando de valores abstratos e irrealizáveis historicamente. As ações profissionais produzem um resultado concreto na vida dos usuários e têm repercussões na vida em sociedade, visto que, nessas ações, estão presentes valores e finalidades de caráter ético-político. Nosso principal desafio, na atualidade, é avaliar o que poderia ser diferente em nossas práticas.

A natureza do trabalho do assistente social é marcada pela sua inserção nas instituições prestadoras de serviços sociais, vinculadas às políticas sociais, em que se volta à regulação das relações sociais e não diretamente à produção material. $\mathrm{O}$ trabalho profissional do assistente social cria condições necessárias ao processo de reprodução social, uma vez que incide sobre as condições de vida dos trabalhadores (por meio de bens e serviços complementares à sua sobrevivência); produz efeitos ideológicos que reforçam ou não a aceitação das condições de compra e venda da força de trabalho e atende às necessidades de normatização e controle dos comportamentos sociais.

\footnotetext{
Observa-se que muitas vezes a perfeita sintonia ente o senso comum e a ação é captada como suficiente para atuação do profissional, principalmente se se trata de situação (ões) que exige $(\mathrm{m})$ solução(ões) rápida(s) ou imediata(s). Isso sanciona a pertinência das opiniões - do saber do senso comum alicerçando atividades - como respostas às demandas postas ao profissional. E aí o relativismo torna-se a regra, já que o pensamento se curva aos ditames da necessidade imediata e a veracidade do conhecimento passa a ser variável da sua utilidade, da sua aplicação prática e da sua capacidade de produzir resultados desejados e/ou previstos. Aqui aparecem requisições socioprofissionais de caráter instrumental, cuja finalidade é em si ou obscura (FORTI; GUERRA, 2013, p. 8).
}

Para autoras citadas, essa maneira de conceber a teoria e a prática está tomando espaço frente às exigências atuais do mercado de trabalho e à crescente mercantilização da formação profissional. 
A teoria nos permite perceber quais são os principais dilemas contemporâneos e como eles se traduzem nas peculiaridades do Serviço Social e se expressam nas exigências e competências socioprofissionais e na cultura profissional.

[...] a teoria não é capaz, por si só, de processar qualquer alteração na realidade concreta, Contudo a prática como atividade efetiva que permita transformação na realidade natural ou social não é uma atividade qualquer, mas atividade que possibilita ao sujeito reflexão sobre sua ação e revelações sobre a realidade [...]. É uma ação capaz de proporcionar conhecimentos, transformando e qualificando nossas ideias sobre as coisas e nos fornecer meios, caso tenhamos intenção de modificá-las (FORTI; GUERRA, 2013, p. 4).

Nesse sentido, o cotidiano profissional pode mostrar-se obscurecido pelos atos repetitivos, objeto de pouca reflexão, caso os profissionais situem equivocadamente seu trabalho e o campo teórico e não apreendam que, em decorrência dos desafios que a realidade lhes impõe diariamente, é necessário conhecimento qualificado e seu constante aprimoramento no exercício profissional, que viabilize uma intervenção crítica, criativa e propositiva.

\footnotetext{
Cabe observar que aqui estamos nos referindo ao assistente social, um profissional de nível superior que, apesar de ser trabalhador assalariado e dos limites definidos pelas instituições empregadoras, tem responsabilidade e chance de escolha, de imprimir sentido, direção valorativa e finalidade às suas ações, uma vez que portador de relativa autonomia na execução da sua atividade. Todavia, para isso, é crucial capacidade intelectual - busca de substanciais conhecimentos teóricos e metodológicos (inclusive ético-políticos) que lhe permitam situar o seu papel como profissional na realidade social - sem obscurecimento de idealismos e dos limites das intervenções que não ultrapassam o plano das intenções, pois desconexas da realidade. Isso requer a busca de conhecimentos que qualifiquem intelectualmente o profissional para escolha responsável do rumo que ele irá tomar [...] (FORTI; GUERRA, 2013, p. 9).
}

Quando pensamos na dimensão ética do exercício profissional, devemos ter em mente que a ética é a capacidade que temos de agir conscientemente com base em escolhas de valor, projetar finalidades e concretizá-las na vida social. A dimensão ética do exercício profissional tem fundamento na liberdade. A liberdade é essa capacidade prática de escolha consciente voltada a uma finalidade, buscando criar condições para a realização objetiva do que foi escolhido, para que novas escolhas possam ser feitas. (BARROCO, 2001). 
As escolhas profissionais nem sempre significam um exercício de liberdade. A escolha livre supõe a existência de alternativas e seu conhecimento crítico, com inteira responsabilidade pelo resultado da ação.

Que escolhas temos que fazer para uma nova experiência no Serviço Social? Quais são as "possibilidades ocultas" nos próprios limites que enfrentamos? O que ainda não foi partilhado na construção da técnica, na manipulação do instrumento, na elaboração do saber, que nos desperta a reconstrução de nosso objeto de intervenção? Objeto este que se manifesta empiricamente, que pode ser elaborado teoricamente e particularizado no cotidiano de nossa inserção profissional, dando legitimidade a nossa identidade em construção.

Há necessidade de nos posicionarmos em face do significado e das implicações da ação profissional e assumir responsabilidades diante de nossas escolhas.

A dimensão ética do exercício profissional é, portanto, um modo particular de objetivação da vida ética. A natureza da ética profissional só pode ser avaliada na dinâmica das transformações sociais, em sua relativa autonomia, em face das condições objetivas que constituem as referências ético-morais da sociedade e rebatem na profissão de modos específicos.

O ethos profissional é "um modo de ser construído a partir das necessidades sociais inscritas nas demandas postas historicamente à profissão e nas respostas ético-morais dadas por ela nas várias dimensões que compõem a ética profissional" (BARROCO, 2001, p. 69). Essas dimensões são as seguintes:

- A dimensão filosófica, que oferece bases teóricas para uma reflexão ética voltada à compreensão dos valores, princípios e modos de ser ético-morais e oferece os fundamentos de uma concepção ética;

- A moralidade profissional e o produto objetivo das ações profissionais (consequências ético-políticas);

- O Código de Ética Profissional, com seus princípios, direitos, deveres, vedações e sanções (BARROCO, 2001, p. 70)

Quando pensamos em sistematização do exercício profissional, devemos recuperar essas dimensões da ética profissional, buscando a unidade entre a teoria e a prática, considerando que teoria transforma as ideias, as consciências, as percepções e as concepções, enquanto a prática se dirige à sociedade em que estamos inseridos e ao objeto 
de intervenção profissional. Precisamos, portanto, de boa base teórica, para compreender essa sociedade e esse objeto de intervenção profissional, sem descuidar do agir profissionalmente.

Se observarmos com atenção nosso Código de Ética Profissional e Lei de Regulamentação da Profissão, veremos que a sistematização é parte constituinte de nossa intervenção profissional. O Código de Ética Profissional traz princípios tais como o pluralismo e a qualidade dos serviços prestados à população que tratam do aprimoramento intelectual.

O assistente social tem direito ao "aprimoramento profissional de forma contínua", devendo esse ser considerado atividade profissional e o ideal é que faça parte do período da jornada de trabalho, o que demanda organização no espaço e no horário de trabalho e, se possível, criação de grupos de estudo para discussão e enfrentamento das situações vividas.

Nos deveres do assistente social para com o usuário, o Código de Ética deixa claro o papel da informação, da participação e do acesso aos usuários. Estudos e pesquisas devem ser feitos, pois são da competência do assistente social e servem para análise da realidade e para subsidiar as ações profissionais (em conformidade com o art. 4으 da Lei de Regulamentação da Profissão). O Código de Ética afirma que esses estudos e pesquisas devem ser devolvidos aos usuários, a fim de que sejam usados para o fortalecimento dos seus interesses. De igual modo, a utilização de materiais de registro audiovisual e pesquisas referentes à população usuária e a forma de sistematização dos dados obtidos devem ser informados a ela, o que supõe autorização para a utilização.

O Código de Ética ainda prevê, enquanto deveres do assistente social, o esclarecimento, no início do trabalho, quanto a objetivos e a amplitude de sua atuação profissional, garantindo a plena informação e discussão sobre as possibilidades e consequências das situações apresentadas e o fornecimento de informações concernentes ao trabalho desenvolvido pelo Serviço Social e suas conclusões. Isso significa que o profissional deve ter em mente o começo, o meio e o fim de sua intervenção profissional, o que também requer alguma forma de sistematização.

Para atingir objetivos mais estratégicos como contribuir para a viabilização da participação efetiva da população usuária nas decisões institucionais, faz-se necessário 
saber: quem são os sujeitos de nossas práticas? Esta é a primeira pergunta que temos que responder ao sistematizar.

Somos levados a lidar com coletivos heterogêneos, cujas práticas envolvem amplo raio de conteúdos teóricos e metodológicos. Que pontos unem a maioria desses sujeitos, suas histórias e suas trajetórias no campo das políticas sociais? Como formular o seu drama cotidiano em linguagem pública de direitos? Como fazê-los acreditar nas instituições, que os submetem a rituais vexatórios, que os expõem publicamente?

A Lei de Regulamentação da Profissão trata (em seu art. 4ํ) como competência do assistente social a realização de estudos socioeconômicos com os usuários para fins de benefícios e serviços sociais, o que, a nosso ver, supõe algum tipo de sistematização. Como orientar diferentes segmentos sociais, no sentido de identificar recursos e fazer uso desses no atendimento e na defesa de seus direitos, se não for feita a sistematização de conhecimentos sobre esses segmentos, recursos e direitos?

Muitas vezes, não nos damos conta, mas caímos numa rotina burocratizada e ativista, prática cada vez mais comum nas instituições em que atuamos. $\mathrm{O}$ apego aos rituais burocráticos, à transformação daquilo que é meio em fim e vice-versa, assim como a "falta de tempo" acabam desestimulando e paralisando projetos de sistematização. Operacionalmente, também nos deparamos com alguns obstáculos, tais como a falta de registros adequados nos instrumentos que utilizamos, ausência de relatórios e informações organizadas; resistências pessoais, institucionais. Como diz Falkembach (1995, p. 28), "entre a vontade de sistematizar uma prática e a criação de condições para tal, passam rios caudalosos".

A seguir, vamos tratar da importância da sistematização para todos os campos de atuação profissional.

\section{A importância da sistematização para todos os campos de atuação profissional}

Partimos do entendimento de que a ação profissional se materializa a partir da formulação de objetivos, que geralmente são condicionados a partir de demandas, necessidades das instituições, dos usuários que estão vinculados a determinado serviço e do Código de Ética Profissional e Lei de Regulamentação da Profissão. A ação profissional, segundo Nogueira e Mioto (2006, p. 9), é: 
Conjunto de procedimentos, atos, atividades pertinentes a uma determinada profissão e realizadas por sujeitos/ profissionais de forma responsável, consciente. Contém tanto a dimensão operativa quanto uma dimensão ética, e expressa no momento em que se realiza o processo de apropriação que os profissionais fazem dos fundamentos teórico-metodológico, e ético-político da profissão em determinado momento histórico.

A sistematização tem a importante tarefa de oferecer subsídios para análise e intervenção do Serviço Social na realidade. É uma postura metodológica que contribui para atribuirmos significado às nossas práticas. Ela pode nos tornar sujeitos de nossas práticas e projetar os nossos passos para além de nós mesmos. Ela ajuda a aguçar nossos sentidos e a mostrar que ainda estamos vivos e na luta por nossos projetos profissionais.

A atividade sistematizadora permite aos sujeitos de uma ação social se apropriarem de sua própria experiência pela construção do sentido de sua vivência (SOUZA, 1997). A sistematização é uma forma metodológica de elaboração do conhecimento. É mais do que a organização de dados, é um conjunto de práticas e conceitos que propiciam a reflexão e a reelaboração do pensamento, a partir do conhecimento da realidade.

Quem passa por um processo de sistematização não permanece o mesmo. Suas práticas, seus valores passam por mudanças e a análise e interpretação desempenha um papel significativo no desencadeamento e na orientação dessas mudanças (FALKEMBACH apud FUMAGALLI; SANTOS; BASUALDO, 2000, p. 11).

Trata-se de construir o sentido da experiência que terá como ação de retorno uma nova forma de interpretar, agir e sentir não apenas a experiência, mas a si mesmo e à sociedade (SOUZA, 1997). Essa é a dimensão ética da sistematização do exercício profissional.

Sistematizar é abrir-se à negociação cultural com o outro, onde houver espaço e condições. Trata-se de um diálogo argumentado para a construção de sentido e rumo a ser seguido conjuntamente (VERONESE, 1999).

Ao sistematizar, não só se atenta aos acontecimentos, mas também às interpretações que os sujeitos têm sobre eles. Cria-se um espaço para que essas interpretações sejam discutidas, compartilhadas e confrontadas (HOLLYDAY, 1996, p. 30). 
Trata-se de um processo que tem a capacidade de levar-nos aos avessos das nossas práticas; à busca de compreender os seus porquês e refletir sobre as consequências que poderão engendrar (FALKEMBACH, 1995).

A sistematização é, portanto, um processo educativo, a fim de que o exercício profissional seja melhor compreendido por si mesmo e pelos outros. Trata-se de desencadear atos de caráter eminentemente reflexivo. Nesse processo de resgate e reflexão sobre a experiência, é possível desvendar e tornar públicos equívocos, incorreções, debilidades, contradições, ao lado do que consideramos acertos e sucessos também alcançados. O processo supõe mudanças, que podem implicar perdas e ganhos, supondo escolhas que são necessárias. Trata-se de uma aprendizagem frente ao fazer.

Há necessidade de (re) visão de rumos, de (re) traçar os caminhos e (re)organizar processos, para alcançar a (re) visão dos sentidos, a (re)significação das nossas práticas no campo das políticas sociais.

\footnotetext{
Trata-se, na verdade, de um esforço crítico, de natureza teórica, sobre a condução da atividade profissional, constituindo-se como um esforço problematizador sobre suas diferentes dimensões em relação às expressões cotidianas da realidade social, mediatizadas pelas políticas sociais, pelos movimentos sociais, pela forma de organização do trabalho coletivo nas instituições e, sobretudo, pelas disputas societárias (ALMEIDA, 2006, p. 403).
}

Sistematizar é refletir a partir de nossa prática, de forma ordenada, crítica, submetendo tudo à crítica, problematizando e identificando os conflitos, as contradições e analisando tudo o que fizemos, buscando os porquês e as relações entre as coisas. É preciso que essa prática se faça de maneira tal que possamos recolher informações, ordená-las, refleti-las e selecionarmos o que é mais importante em nossas experiências. Para isso, é importante parar no caminho, para se perceber como parte de um processo que tem resultados e, quem sabe, mudar a forma como atuamos. É nesse processo que recolhemos a informação, refletimos e selecionamos o mais importante das experiências.

É importante sistematizar, porque perdemos no esquecimento experiências interessantes que realizamos. Poucas vezes nos damos conta do que ocorre, dos contratempos e contradições que nos impedem de avançar.

Sistematizar é ordenar e classificar a informação; é criticar o processo vivido; aprender ou tirar lições com a experiência. Primeiramente, há um momento descritivo, de 
reconstrução histórica do que passou. Depois, há que se interpretar criticamente esse processo vivido e tirar as conclusões. O mais importante é quando somos capazes de comunicar as aprendizagens. A ideia é que cada um de nós discorra sobre parte de sua experiência.

Não há receita para a sistematização, mas geralmente temos um tema comum e aspectos comuns que queremos sistematizar. Então, disso resulta que cada profissional vai elaborar sua resposta e compartilhá-la. A sistematização serve, portanto, para alimentar avaliações e planejar ações mais consequentes na realidade.

Em suma, a sistematização tem como objetivo realizar a interpretação crítica do processo vivido; visando procurar as relações entre a teoria e a prática. Quem realiza deve ter sido parte do processo que se sistematiza. Ela expressa as aprendizagens alcançadas nos processos vividos.

\section{A articulação entre sistematização do exercício, condições de trabalho e demandas de usuários das políticas sociais.}

Ao longo de sua história, o Serviço Social tem conseguido forjar um conjunto de procedimentos de registro e avaliação de suas atividades, desde relatos de suas abordagens individuais ou grupais até reuniões de equipe, ocupando-se de produzir informações e organizar processos em que a sua prática pudesse ser objeto de reflexão. Embora fosse regular o procedimento de registrar dados, não houve a construção de uma cultura profissional alimentada por atividades investigativas, com sistematização do trabalho no Serviço Social.

Para Almeida (2006, p. 401), os procedimentos de registro acabam por configurar a burocracia institucional em que atua o assistente social, e as reuniões de equipe carecem de objetividade, porque estão ausentes os instrumentos necessários aos processos de reflexão e avaliação do trabalho.

Sabemos que políticas, estratégias, diretrizes (princípios normativos que dão unidade à ação, englobando diferentes aspectos que compõem o trabalho) e prioridades institucionais estão, a todo o momento, plasmando- se na demanda que recebemos, mas esta somente existe porque uma problemática desafia a ação institucional, e está inscrita no campo das questões mais amplas da conjuntura municipal, estadual, nacional e 
internacional. Não podemos desprezar, no entanto, que a demanda institucional também é determinada historicamente pelos modos de ser e de aparecer das relações na sociedade capitalista, que tem particularidades à brasileira, que se expressam de muitas formas: "jeitinho brasileiro", "toma-lá-dá-cá", "política do favor e do compadrio", do "você sabe com quem está falando?" etc.

Em vista disso, as normas institucionais têm um sentido e uma finalidade, não sendo procedimentos descritivos apenas do modo de funcionamento da organização. Elas fundamentam e sustentam, por assim dizer, uma determinada ideologia (que, como sabemos, oculta e dissimula a realidade dos fatos, contribuindo para determinadas formas de dominação, quando não desvendadas e problematizadas pela reflexão cotidiana). Portanto, não podemos ignorar que os procedimentos, os dispositivos e o discurso desses dispositivos não se separam da maneira como são vividos pelas pessoas e dos valores com os quais elas estão engajadas e comprometidas. Ou seja, os dispositivos operacionais se vinculam à ideologia, como forma de as pessoas interiorizarem determinadas condutas, legitimando-as, bem como aos princípios que as regem.

[...] tem-se claro que as normas institucionais são construídas e operadas pelos sujeitos, portanto, nem sempre assimiladas e assumidas da mesma forma - elas podem ser aprofundadas ou subvertidas: relações independentes das formais podem ser estabelecidas, trabalhos alternativos podem emergir dentro da instituição e, por sua competência, constituir grupos de referência que a ultrapassem. Nesse sentido, é fundamental analisar a dinâmica interna e a estrutura das relações da instituição na qual se opera o projeto. A análise da equipe - seus valores, suas características - irá permitir identificar situações que podem tanto potencializar o alcance de seus resultados (BATISTA, 2003, apud AZEVEDO, 2008).

Embora a leitura sobre a realidade seja o ponto de partida para subsidiar as decisões tomadas sobre as manifestações da questão social, canalizando as demandas da população para projetos, programas e planos no âmbito institucional, ainda não conseguimos algumas conquistas importantes como condições dignas de trabalho, ${ }^{1}$ para atender ao nosso

\footnotetext{
${ }^{1}$ Segundo a Resolução CFESS no 493, de 21 de agosto de 2006, "dispor de condições de trabalho condignas" - algo disposto no artigo 7o, "a" do Código de Ética, como direito do assistente social - supõe existência de espaço físico para abordagens individuais e coletivas com iluminação adequada; recursos que garantam a privacidade do usuário; ventilação adequada; com portas fechadas e espaço adequado para colocação de arquivos para a guarda de material técnico de caráter reservado (BARROCO; TERRA, 2012). 0 artigo 13, "a" do Código de Ética afirma que o assistente social tem o dever de denunciar ao CRESS as instituições onde as condições de trabalho não sejam dignas ou possam prejudicar os usuários ou profissionais. Antes, porém,
} 
usuário com dignidade, que nos permitam construir vínculos de pertencimento e de reconhecimento civil, diante de sua problemática.

A inércia dos dados fichados se mistura ao intenso fluxo de informações, que, longe de contribuírem para a qualificação dos serviços, parecem ser um "arquivo morto". No entanto, nós sabemos que eles estão vivos e somente o contato entre o significado da linguagem das pessoas e a realidade concreta é que nos permite o acesso aos nexos de nossa intervenção, indo para além da prática instituída. Ter uma visão totalizadora da problemática que nós enfrentamos, organizando nossa rotina para, em algum momento do dia, pensar sobre o que estamos fazendo é fundamental nesse sentido. Porém, não dispomos de computadores que nos permitam informatizar os dados contidos nas fichas dos usuários, que são fontes ricas de conhecimento, mas acabam "esquecidos" num arquivo, cuja organização não facilita muito o trabalho de sistematização, porque fichas antigas e atuais se misturam. A quem interessa isso?

A reflexão voltada, reiteradamente, aos dados coletados por meio de entrevistas, questionários e formulários pode nos conduzir à análise e ao estudo de alternativas, à superação e à reconstrução de conceitos e práticas de diferentes disciplinas, com a explicitação, quantificação e qualificação dos fatos sociais, sobre os quais precisamos projetar nossas ações.

Ao mesmo tempo que refletimos, estamos decidindo, escolhendo as alternativas, determinando os meios por meio dos quais alcançaremos nossos objetivos e projeções, estipulando prazos para isso.

Quando "deixamos o barco correr", não tendo clareza sobre onde começa e onde termina o que estamos fazendo, e, simplesmente, não nos determinamos a fazer o que precisa ser feito: a execução das ações projetadas deve se operar em consonância com a reflexão e a decisão que tomamos, seguindo-se de uma nova reflexão sobre os processos e as consequências inscritas nas relações de poder, com vistas à sistematização da prática, à luz de uma teoria que a ilumine os caminhos.

é necessário que o assistente social informe por escrito as inadequações constatadas quanto às condições éticas, técnicas e físicas, sugerindo alternativas para melhoria dos serviços. 
Podemos fazer um estudo reiterado e crítico das práticas cotidianas, encontrando o fio condutor para novas práticas. Embora isso não seja permitido institucionalmente, precisa ser conquistado profissionalmente, cotidianamente.

Essa conquista se materializa pela documentação, não a institucional (para quem só se importa com as estatísticas), mas a feita pelo profissional, que lhe permite o registro da ação desenvolvida por meio de relatórios descritivos (e não sintéticos) das entrevistas, das reuniões, visitas, abordagens, encaminhamentos e outros instrumentos desenvolvidos na relação com os usuários, com a instituição onde se trabalha e com as outras com quem estabelece possíveis parcerias. Um diário de observações (ou caderno de campo) poderá ser rico para avaliações subsequentes, e não deve ser deixado à vista de outros profissionais, mas mantido em sigilo, como modo de preservar-se nessa relação institucional.

No dia a dia das instituições, a documentação vem servindo ao controle sobre a ação dos profissionais, ou é entendida pelos próprios assistentes sociais como um instrumento administrativo, burocrático ou como uma obrigação para justificar ou prestar contas de nossa ação junto à direção, reforçando assim seu caráter controlista. "Acabamos sendo vítimas e algozes ao mesmo tempo" (MARCOSIN, 2013, p. 65). Segundo a autora, isso empobrece e desqualifica a documentação, pois limita as possibilidades de análise, intervenção na realidade e produção de conhecimentos.

“[...] documentar é registrar, sendo, portanto, um instrumental-técnico, uma mediação valiosa no processo de materialização da relação entre a teoria e a prática no trabalho profissional" (MARCOSIN, 2013, p. 68).

A documentação, portanto, terá a direção política dada à ação social como um todo. Pode ser um simples "roteiro de papéis a serem preenchidos e organizados", perpetuando o caráter controlista e burocrático, como se fosse um filtro de informações que costuma atender apenas aos interesses institucionais. Ou pode, com clareza de dicção e finalidade política de nossa intervenção, ser um meio de trabalho, instrumental técnico para auxiliar no deciframento das tendências constantes da realidade, as quais, uma vez desvendadas, podem vir a ser acionadas pela vontade política dos sujeitos - assistentes sociais e usuários - de forma a retirar dos dados e das análises deles as estratégias de ação, estabelecendo a relação dialética entre a teoria e a prática. 
Os registros feitos devem ser apreciados sobre o ponto de vista da redação, da clareza e precisão dos argumentos, das referências que o profissional se apropria teóricometodologicamente, na legislação social, institucional e/ou profissional. É preciso verificar se o documento feito contém inter-relação e coerência entre seus diferentes itens, se o que se prioriza na descrição e análise trata-se de um problema significativo (se realmente for, podemos explicar por que o é; e fazer uma oportuna abordagem sobre ele e apresentar a alternativas consistentes para o que está sendo abordado, com justificativas plausíveis para isso).

Cabe ao assistente social, na condição de sujeito portador de poder (pelo lugar que ocupa na instituição), de um discurso (fruto de sua visão de mundo), veiculado por meio da linguagem, assumir uma atitude de autoquestionamento constante na relação que estabelece com a população usuária dos serviços sociais. Numa relação profissional, estão em jogo seus interlocutores, a situação e o contexto sócio-histórico e ideológico. Há, portanto, uma pluralidade de discursos e práticas profissionais. O verdadeiro serviço que prestamos a movimentos e indivíduos consiste em fazer com que sua voz seja ouvida, em levá-la para fora, em pôr fim à sensação de isolamento e impotência, em conseguir que seu discurso chegue a outras pessoas e comunidades (PORTELLI, 1997, p. 31).

Quando somos capazes de decodificar um conjunto de questões que se colocam em nossa prática, em determinado momento, certamente somos capazes de descobrir o extraordinário sobre o ordinário e sobre o trivial cotidiano. Para tanto, precisamos, antes de tudo, elaborar conscientemente nossa posição e discernir o que permitimos que os outros fizessem conosco (no cotidiano das instituições em que trabalhamos) e o que fazemos disso, porque não somos objetos de poder, tão somente. Somos também sujeitos desse poder, ainda que, muitas vezes, não lidemos com ele de forma consciente. Reverter o curso de nossa história, mudar a trilha depende de nós, das escolhas que nós fazemos afinal, somos livres para decidir nossas vidas.

A sistematização tem como ponto de partida a busca de referenciais teóricometodológicos que orientarão o estudo das situações, prevendo seus limites e suas possibilidades, propondo objetivos, definindo estratégias de ação, com reconhecimento do objeto de intervenção profissional e dos resultados que vão sendo alcançados a cada momento. Isso pressupõe um estudo apurado das demandas sociais, institucionais e 
profissionais, com o foco voltado à reconstrução do objeto da intervenção profissional (BAPTISTA, 2000).

O primeiro passo é a identificação da necessidade de sistematização, ou seja, é preciso descrever as razões que podem levar o assistente social a afirmar que é preciso sistematizar seu exercício profissional. Ao explicitar as razões, tem-se a formulação de um problema/objeto de estudo desse processo de sistematização. Deve-se, a seguir, responder a seguinte pergunta: formulado este objeto de estudo, ele vai servir para quê?

Os objetivos vão servir para definir o campo empírico para a atividade sistematizadora do exercício profissional. O segundo momento é a busca de fundamentos teórico-metodológicos para essa atividade sistematizadora. Parte-se do entendimento de que quem sistematiza não é o primeiro a tratar do objeto de estudo escolhido. $O$ objeto de sistematização já foi tratado/estudado por outros. Portanto, é importante fazer uma revisão de literatura sobre o assunto. Consultar a bibliografia existente sobre o objeto de estudo ou similar, à qual possa ter acesso. Existem compreensões plausíveis sobre o objeto de estudo e é importante estudá-las, porque é possível que se descubra o sentido da questão ou da experiência a partir de outras opiniões, não havendo necessidade de sistematização sobre esse assunto, mas de outro, ou se pode chegar a uma formulação mais adequada aos interesses do profissional.

A sistematização é a busca de apropriação da experiência ou da vivência pelos próprios sujeitos que a realizaram. É preciso, portanto, indagar: qual é a concepção do objeto de estudo da qual partimos? Essa construção deve ser feita a partir de estudos anteriores, ou seja, da revisão de literatura, mas também do que propõe a intervenção institucional sobre aquele assunto diretamente ou de inferências que podem ser elaboradas a partir de seus documentos oficiais. Como vamos proceder para encontrar as informações que permitirão a construção dos dados que garantirão a reconstrução do objeto, isto é, a resposta ao problema de sistematização? Trata-se de planejar o trabalho de campo e de interpretação.

Existem possíveis respostas à pergunta elaborada, que representa o problema/objeto de estudo. Tais respostas são suposições que constituem a concepção da qual se parte para a atividade sistematizadora. A visão do objeto de estudo tem que se dar antes da atividade de sistematização. Aquelas suposições serão confrontadas com as 
descobertas feitas no trabalho de interpretação a partir das informações obtidas no trabalho de campo.

O terceiro passo do planejamento será o detalhamento do trabalho de campo e o processo de interpretação, das argumentações que surgem quando voltamos ao trabalho de campo e da incorporação das novas contribuições que emergirem desse processo. Nesse processo, existem pessoas que vão se identificar e participar direta e ativamente dos processos de sistematização. É preciso organizar o calendário, distribuindo atividades no tempo e no espaço, definindo responsabilidades. A seguir, é preciso esboçar a forma de divulgação dos resultados da construção, a comunicação da construção que foi possível por meio da sistematização.

Para Paulo Netto (1989, p. 150), a sistematização da prática traz para a profissão a possibilidade de otimizar sua própria intervenção prática, organizando e generalizando a experiência dos assistentes sociais e cristalizando pautas de procedimento profissional, reconhecidas como tais e transmissíveis via formação institucional. Por outro lado, é um passo necessário para o embasamento profissional, na medida em que viabiliza o movimento de constituição de uma elaboração teórica particular ao objeto sobre o qual incide a ação profissional.

\section{Considerações finais}

Estamos falando do Serviço Social como uma profissão que tem por base uma ação contínua sobre um conjunto de situações, em determinado momento histórico, que está envolvida por atos decisórios, ordenados em momentos definidos e baseados em conhecimentos teóricos, científicos e técnicos. Somos desafiados por uma complexidade de problemas que exigem de nós não apenas reparações e arranjos institucionais, mas, sobretudo conhecimento profundo de sua origem e desenvolvimento no campo das relações sociais, políticas, econômicas e culturais e da intenção dos que os abordam.

Temos acesso, no âmbito do Serviço Social, a uma série de dados empíricos, relacionados às condições de vida e de reprodução da população, à implementação cotidiana das políticas sociais e às características culturais e políticas dos diversos segmentos sociais. Podemos passar anos sem trabalhar esses dados, sem investigar, sem sistematizar e sem produzir conhecimentos sobre eles. 
No entanto, interpretar a realidade da qual fazemos parte, juntamente aos sujeitos usuários do Serviço Social, constitui-se um processo interventivo, que deveria nos demandar um conhecimento a priori dessa mesma realidade, como forma de ressignificar espaços; pensar coletivamente alternativas de enfrentamento da questão social; redescobrir potencialidades; associar experiências; buscar construir identidades coletivas, respeitando a diversidade no campo da igualdade jurídico-política, dando visibilidade às fragilidades para tentar superá-las; desvendar bloqueios, contradições, processos de alienação; revigorar energias, vínculos, potencial organizativo, reconhecendo espaços de pertencimento, mediante vínculos formais e informais de cidadania. Mas sem conhecimento, pouco ou nada podemos de fato. Isso porque todas essas finalidades só serão alcançadas quando o assistente social se debruçar sobre os dados e informações que gera, por meio de uma série de procedimentos interventivos (entrevistas, reuniões, visitas domiciliares etc.), para organizá-los e analisá-los, a partir de uma postura críticoinvestigativa.

A sistematização recobra a dimensão intelectual da atividade profissional, na medida em que põe em marcha uma reflexão teórica sobre alguma dimensão da experiência, podendo reordená-la, colaborando para que novas técnicas sejam operacionadas em consonância aos objetivos propostos e ao aporte teórico-metodológico.

Talvez seja preciso demarcar aqui que, na perspectiva dialético-crítica, a centralidade é atribuída à finalidade e não ao instrumental em si mesmo. Marx $(1993$, p.12) já havia alertado para o fato de que é na práxis que o homem deve demonstrar a verdade, a realidade, o poder e o caráter terreno de seu pensamento.

A sistematização pode significar muitas coisas ao assistente social, desde autonomia até legitimidade no espaço em que atua, passando, logicamente, pelo reconhecimento dos limites, avanços e contribuições efetivas do Serviço Social no processo de construção da cidadania. O importante é construir, no âmbito da própria rotina institucional, espaço para investigação e socialização de experiências, que mostre os procedimentos mobilizados como potencializadores e problematizadores das questões relativas ao trabalho do assistente social.

Por trás de tudo isso está, logicamente, uma concepção de profissão, de instituição e de sociedade que, do nosso ponto de vista, é tensionado por necessidades e interesses 
diversos. A direção a ser dada à sistematização dos dados e informações reforça um determinado projeto de manutenção ou de transformação das relações entre assistente social e usuário da política social e da instituição, entre esses e a instituição, entre esses e a sociedade, entre esses e o Estado. Ao problematizarmos tais relações, devemos estar prontos para o debate e o embate que temos que travar e enfrentar as consequências objetivas e subjetivas nessas relações que instituímos de fato, quando damos início ao processo de sistematização da prática. A clareza disso deve acontecer do ponto de vista teórico, político e ético.

Como podemos analisar, pode existir, nos procedimentos interventivos do assistente social, a predominância de um dispositivo informacional fechado e mutilador de um efetivo debate e embate no processo grupal. Nesse caso, há um tipo de "participação consentida", na medida em que os discursos servem mais para a confirmação e o reforço da ideologia instituída e veiculada pelo assistente social (VELOSO, 1995). Para Veloso, o uso de estratégias e recursos técnico-operativos deve permitir a coexistência da concórdia e da discórdia, do consenso e do dissenso. É preciso transformar o âmbito profissional num espaço onde se dê um processo efetivo de negociação, tensão e resistência.

A produção e a reprodução de ideias e valores, ideologias, culturas, representações morais não são construídas fora dos espaços das condições de vida e de trabalho das classes.

Entre a vontade de sistematizar a prática e a criação de condições para tal, há muitas questões a serem resolvidas, desde as conjunturais como as que enfrentamos, impedindo o desenvolvimento de muitos trabalhos, até as resistências pessoais, institucionais, o exigente cotidiano do assistente social e a dificuldade de conseguirmos recursos financeiros com entradas regulares. Tudo isso sem perder de vista o contexto e as armadilhas que nos apresenta a política neoliberal.

As experiências que vimos construindo historicamente, no campo do Serviço Social, têm nos mantido distantes da sistematização de conhecimentos, visto que as demandas de trabalho são imensas, os conteúdos dessas demandas são demasiadamente amplos e de larga importância estratégica aos usuários das políticas sociais, e as nossas debilidades institucionais e pessoais são, também, inumeráveis. Raramente nos damos direito ao ócio criativo, tão necessário à produção de conhecimentos. 
Temos que encontrar caminhos para romper com tensões como essa, nos limitando a algumas prioridades, o que ajuda a atribuir maior densidade teórica ao nosso fazer.

Na sistematização, a construção do objeto demanda análises profundas. A narrativa da prática é o objeto da reflexão e o resultado disso é a produção do discurso, sob dinâmica de questionamento permanente. A sistematização é um espaço de encontro entre sujeitos plurais (assistentes sociais, usuários, demais profissionais, representantes de instituições, de políticas sociais), que se congregam por uma insatisfação, busca, necessidade e/ou curiosidade. E adiantar que o mínimo que a sistematização pode fazer é possibilitar que esses sujeitos, em seus processos interativos, expandam essas marcas e impulsionem novas práticas sociais.

Precisamos ter claro que nossa memória tanto pode acompanhar quanto resistir às mudanças. O fazer ou não fazer a sistematização de nossa prática é uma decisão nossa, mas não podemos perder de vista a natureza interventiva do Serviço Social, pois a memória de nossa profissão não registra tão somente o que aconteceu no passado, como também aquilo que deixou de acontecer, mas também aquilo que poderia ou deveria ter acontecido.

\section{Referências}

ALMEIDA, N. L. T. Retomando a temática da "sistematização da prática" em serviço social. In: MOTA, A. E. et al. (Org.). Serviço social e saúde: formação e trabalho profissional. São Paulo: Cortez, 2006.

AZEVEDO, I. S. (Re)Pensando o serviço social. 2008. Disponível em: <http://repensandooservicosocial.blogspot.com.br/2008_10_01_archive.html>. Acesso em: 1 abr. 2014.

BAPTISTA, M. V. Planejamento social: intencionalidade e instrumentação. 2. ed. São Paulo: Veras, 2000. (Série livro-texto, 1).

BARROCO, M. L. S. Ética e serviço social: fundamentos ontológicos. São Paulo, Cortez, 2001.

BARROCO, M. L. S.; TERRA, S. H. Código de ética do/a assistente social comentado. São Paulo: Cortez, 2012.

BRASIL. Resolução CFESS no 493/2006 de 21 de agosto de 2006. Dispõe sobre as condições éticas e técnicas do exercício profissional do assistente social. Disponível em: <http://www.cfess.org.br/arquivos/Resolucao_493-06.pdf>. Acesso em: 1 abr. 2014. 
FALKEMBACH, E. M. F. Sistematização... Juntando cacos, construindo vitrais. ljuí: Ed. UNJUÍ, 1995. (Cadernos UNJUÍ, 23).

FORTI, V.; GUERRA, Y. Na prática a teoria é outra? In: (Org.). Serviço social:

temas, textos e contextos. 4. ed. Rio de Janeiro: Lumen Juris, 2013.

FUMAGALLI, D.; SANTOS, J. M. P.; BASUALDO, M. E. (Org.). O que é sistematização? Uma pergunta, diversas respostas. São Paulo: CUT Brasil, 2000.

HOLLIDAY, O. J. Para sistematizar experiências. João Pessoa: Ed. UFPB, 1996.

MARCONSIN, C. Documentação em serviço social: debatendo a concepção burocrática e rotineira. In: FORTI, V.; GUERRA, Y. (Org.). Serviço social: temas, textos e contextos. 4. ed. Rio de Janeiro: Lumen Juris, 2013. p. 65-76.

MARX, Karl. A ideologia alemã. 9. ed. São Paulo, Hucitec, 1993.

NOGUEIRA, V. M. R.; MIOTO, R. C. T. Sistematização e avaliação das ações dos assistentes sociais no campo da saúde. In: MOTA, A. E. et. al. Serviço social e saúde: formação e trabalho profissional. 2006. Disponível em: <http://fnepas.org.br/pdf/servico_social_ saude/inicio.htm>. Acesso em: 1 abr. 2014.

PAULO NETTO, J. Notas para a discussão da sistematização da prática em Serviço Social. Cadernos ABESS, São Paulo, n. 3, 1989.

PORTELLI, A. Tentando aprender um pouquinho: algumas reflexões sobre a ética na história oral. Projeto História, São Paulo, n. 14, p. 7-24, fev. 1997.

SOUZA, J. F. Sistematização da experiência por seus próprios sujeitos. Tópicos Educacionais, Recife, v. 15, n. 1/3, 1997.

VELOSO, L. H. P. Processo de trabalho do serviço social (do despreparo teórico às transgressões do ofício). Em Pauta, Rio de Janeiro, n. 6, p. 30-50, nov. 1995.

VERONESE, C. D. Sistematização: uma alternativa de investigação aplicada aos processos de mudança social. São Paulo, 1999. Texto de circulação interna Projeto Integral. 